\title{
Preparation and Characterization of Activated Carbon from Iraqi Khestawy Date Palm
}

\author{
Falah H. Hussein, ${ }^{1}$ Ahmed F. Halbus, ${ }^{1}$ Abbas J. Lafta, ${ }^{1}$ and Zahraa H. Athab ${ }^{2}$ \\ ${ }^{1}$ Chemistry Department, College of Sciences, Babylon University, Hilla, Iraq \\ ${ }^{2}$ Environmental Researches Center, Babylon University, Hilla, Iraq \\ Correspondence should be addressed to Falah H. Hussein; abohasan_hilla@yahoo.com
}

Received 16 December 2014; Revised 25 June 2015; Accepted 10 August 2015

Academic Editor: Mohammad A. Al-Ghouti

Copyright (C) 2015 Falah H. Hussein et al. This is an open access article distributed under the Creative Commons Attribution License, which permits unrestricted use, distribution, and reproduction in any medium, provided the original work is properly cited.

This work includes a synthesis of three types of the activated carbon (AC) from three different positions from the same Iraqi Khestawy date palm. These three positions are the palm fronds (AC1), the date palm seeds (AC2), and the palm fiber (AC3). These three types of AC were synthesized by a physiochemical activation method using the same activator which was $\mathrm{H}_{3} \mathrm{PO}_{4}$. These materials were investigated using different techniques such as Fourier transform infrared spectroscopy (FTIR) and scanning electron microscopy (SEM). The adsorption activity of the synthesized AC samples was investigated by following the removal of both Bismarck brown G (BBG) and reactive yellow dye 145 (RY145). Both the kinetics of adsorption and the removal percentage of these dyes were investigated from the batch tests in this study. Different reaction parameters and conditions for adsorption processes were investigated. Also an investigation of both Langmuir and Freundlich adsorption isotherms was considered. The different physical properties of these materials were undertaken such as the point zero charges of the synthesized samples (PZCs), the percentage of humidity, and the adsorption capacity also being investigated. The activity of these materials in the removal of $\mathrm{BBG}$ from the aqueous solution was as follows: $\mathrm{AC} 1>\mathrm{AC} 2>\mathrm{AC} 3$.

\section{Introduction}

Activated carbon (AC) is a type of carbonaceous materials. It normally differs from elemental carbon by the oxidation of carbon atoms that are present on the inner and outer surfaces [1]. Recently, these materials have become an important research area due to their excellent properties. This involves their large specific areas, nontoxicity, high porosity, and the ability of their tunable surface to contain different functional groups. According to these properties, AC types have been widely used as adsorbent materials for a wide range of applications [2-4]. They can be used to adsorb materials with a high capacity from gas and liquid phases. AC is used in wastewater treatment, the purification of drinking water, gas phase adsorption in air pollution, and liquid phase adsorption. AC has a high applicability in adsorption which arises from its high porosity, rapid adsorption, and thermal stability. Until now, synthesized AC has been relatively expensive, so that the synthesis of a relatively cheap and commercially available AC for mass applications seems to be an interesting challenge [5-8]. This aim can be approached via the use of inexpensive and widely available raw materials [9]. These AC raw precursors include using agricultural wastes as inexpensive raw materials with high carbon contents and low inorganic contents. Currently, an important application of AC is the removal of polluted dyes from industrial wastewater. It is well known that industrial effluents produced from different industrial and human activities can cause high levels of environmental pollution as these wastes are highly colored and contain large amounts of toxic organic species $[10,11]$. Currently, more than $7 \times 10^{5}$ tons of wastewater containing dyes and pigments stuff is produced annually worldwide $[12,13]$. The disposal of this colored water into the surrounding environment results in the contamination by these polluted materials of the soil and/or water. In terms of industrial wastewaters, an important class of polluted materials comprises dyes and pigments. This material can affect the environment for both toxicological and environmental reasons $[14,15]$. However, these dyes are not biodegradable and are costly. On the other hand, the physical 
and chemical processes involved in the dyes removal are more adequate in comparison with biodegradable method but they are very costly and cannot be used for mass applications. Consequently, adsorption processes seem to be the best method for the dyes removal. Out of the different adsorbents, activated carbons appear promising [16, 17]. However, AC is widely used as a standard adsorbent for the removal of a wide range of polluted dyes from colored wastewaters. Recently, activated carbon has been considered as an important type of adsorbents due to its high microporosity with a high surface area and nontoxicity [18]. Thus, it can be used as a good adsorbent for a wide range of adsorbates. This process can be performed by using AC in both powder and granular phases. For this reason, many researchers have been focused on the development of low cost adsorbent materials. These adsorbents involve sugarcane, bagasse, soy meal hull, orange peel, saw dust, palm ash, rice husk, rice straw, and flay ash $[19,20]$.

In this study, activated carbon has been synthesized by using a physiochemical activation method from different three positions from the same Khestawy Iraqi date palm using phosphoric acid as activators for two of the cases. It is well known that Iraq is famous globally for its agriculture of many classes of date palms and due to the fact that these precursors' raw materials are available widely. Therefore, this project can be developed for use in mass applications. The activity of AC was investigated by the adsorption of Bismarck brown $\mathrm{G}$ and reactive yellow dye 145 as a model of a polluted dye from their aqueous solutions.

\section{Experimental Part}

2.1. Adsorbate. The adsorbates that were used in this study were the Bismarck brown $\mathrm{G}\left(\mathrm{C}_{18} \mathrm{H}_{20} \mathrm{~N}_{8} \mathrm{Cl}_{2}\right)$ and reactive yellow dye $145\left(\mathrm{C}_{28} \mathrm{H}_{20} \mathrm{ClN}_{9} \mathrm{Na}_{4} \mathrm{O}_{16} \mathrm{~S}_{5}\right)$. These dyes were used as adsorbed dye models in this study and they were used as provided without any further purification. Distilled water was used to prepare all the solutions and reagents in this work.

2.2. Synthesis of the Activated Carbon. Each of $\mathrm{ACl}, \mathrm{AC} 2$, and AC3 was synthesized from raw materials that were collected from different parts of the same Iraqi Khestawy date palm (IKDP). For each sample, the raw materials were washed with hot distilled water several times to remove dust and other wastes. After that the samples were dried at $110^{\circ} \mathrm{C}$ for two hours. Then the resultant dry materials were mixed with the desired activator at the appropriate ratio in a chemical activation process. This process involved heating materials at $700^{\circ} \mathrm{C}$ in a graphite furnace for one hour in an inert atmosphere by flushing nitrogen prior to and during heating time. After that, the resultant samples were cooled to room temperature and the $\mathrm{pH}$ of the samples was adjusted around the value of 7 by washing with distilled water. Then the final products were dried at $110^{\circ} \mathrm{C}$ for two hours to yield the final activated carbon. Photographic image of Iraqi Khestawy date palm is shown in Figure 1.

2.3. Adsorption Studies. The influence of different parameters on adsorption processes was investigated in this work.

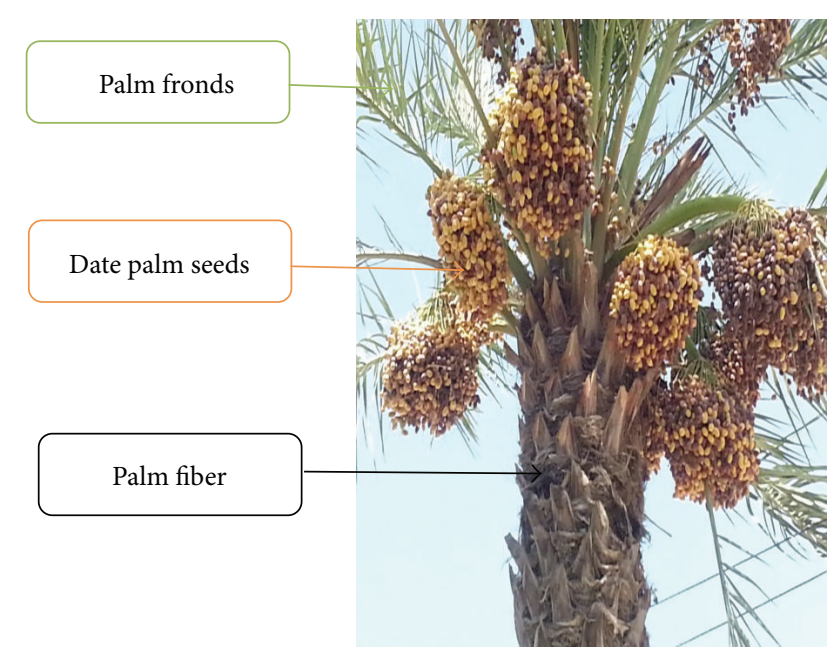

FIGURE 1: Diagrammatic representation of Iraqi Khestawy date palm structure.

Adsorption processes were performed in magnetic stirrer under air atmosphere. The processes of adsorption were studied using an initial concentration of $40 \mathrm{ppm}$ of the used dyes in this study. The adsorbent was loaded in different concentrations in a solution of $100 \mathrm{~mL}$ of aqueous solutions of the dye. These masses were $0.01,0.05,0.10,0.15$, and $0.20 \mathrm{~g}$. During run of adsorption processes and periodically $2 \mathrm{~mL}$ of the reaction mixture was withdrawn from the reaction mixture. Then, this volume of reaction mixture was centrifuged and the absorbance recorded at a wavelength of 448 and $416 \mathrm{~nm}$ for BBG and RY145, respectively. For both cases, the optical density of the supernatant liquid was recorded using Spectrometer photometer Shimadzu 1650 PC-UV-visible. The efficiency for dye removal from the aqueous suspension $(R \%)$ was estimated using the following relationship [21-23]:

$$
R \%=\frac{C_{i}-C_{f}}{C_{i}} \times 100
$$

From the above equation, $C_{i}$ is the initial concentration of both BBG and RY145 dyes and $C_{f}$ is the final concentration after one hour of the adsorption process. The term $q$ refers to the amount of the dye adsorbed on the adsorbent in $\mathrm{mg} / \mathrm{g}$. Adsorption capacity at a given time of the adsorption is $q_{t}$ and this can be calculated according to the following relationship:

$$
q_{t}=\frac{\left(C_{i}-C_{t}\right) \times v}{m} .
$$

The term $C_{t}$ refers to the concentration of the used dyes as a function of time, $v$ refers to the volume of solution, and $m$ is the mass of the used adsorbent in this work.

2.4. Adsorption Capacity of the Synthesized Activated Carbon. Adsorption uptake capacity of each of $\mathrm{ACl}, \mathrm{AC} 2$, and $\mathrm{AC} 3$ was determined by suspension of $0.1 \mathrm{~g}$ of each of $\mathrm{ACl}, \mathrm{AC} 2$, and AC3 in an aqueous solution of methylene blue (MB) $100 \mathrm{~mL}, 20 \mathrm{ppm}$. The resultant mixture was suspended and 
shacked in air atmosphere at room temperature for $24 \mathrm{hrs}$. This mixture then was centrifuged three times to insure complete removal of all fine particles of the AC. The absorbance of the resultant clear solution was recorded at $665 \mathrm{~nm}$ using UV-visible spectrophotometer. The adsorption capacity was calculated using a suitable calibration curve of standard solutions of $\mathrm{MB}$. Then the adsorption uptake capacity of each of $\mathrm{AC} 1, \mathrm{AC} 2$, and $\mathrm{AC} 3$ was evaluated by comparing these concentrations with the initial concentration of $\mathrm{MB}(20 \mathrm{ppm})$ [24]. These results are shown in Table 2.

2.5. Humidity of the Synthesized Activated Carbon. Humidity content for the AC samples was estimated as a humidity percentage by subjecting $0.10 \mathrm{~g}$ of dried AC to the ambient lab atmospheric conditions for 24 hours. Then these samples were weighed accurately and dried in oven at $110^{\circ} \mathrm{C}$ for one hour. After drying, the samples were reweighed accurately and the humidity percentage was calculated from differences in the weights for the desired sample [25]. The results of humidity for each of $\mathrm{AC} 1, \mathrm{AC} 2$, and AC3 are summarized in Table 3.

2.6. The Point Zero Charge of the Activated Carbon Samples (PZCs). The isoelectric point of these materials was investigated as point zero charges. The PZCs values for all the AC samples were calculated according to the potentiometric titration [26]. In this method, $100 \mathrm{~mL}$ of $0.03 \mathrm{M} \mathrm{KNO}_{3}$ was used as a blank solution and to this amount of the blank $\mathrm{NaOH}(1 \mathrm{~mL}$ of $1 \mathrm{M})$ was added. Then the formed mixture was titrated against $\mathrm{HNO}_{3}(0.10 \mathrm{M})$. A mixture that is formed of $100 \mathrm{~mL}$ of $\mathrm{KNO}_{3}$ with $0.10 \mathrm{~g}$ of the $\mathrm{AC}$ was stirred in air atmosphere for 24 hours. Then, $1.0 \mathrm{~mL}$ of $\mathrm{NaOH}$ was added and it was titrated with $\mathrm{HNO}_{3}$. The obtained results were plotted as a volume of the added acid against $\mathrm{pH}$ of the mixture. The obtained intersection point for each case was taken to be equal to the PZC of the investigated AC. These results are shown in Table 4.

2.7. Scanning Electron Microscopy (SEM). Surface morphology of the AC samples was investigated using Scanning Electron Microscope Inspect 550, Netherland. This equipment was operated at $25 \mathrm{kV}$ and prior to run in SEM machine, the AC samples were dried and they were adhesive on carbon tape attached to aluminum-stubbed sputter coated with platinum. SEM images of AC1, AC2, and AC3 are shown in Figure 7.

2.8. Frontier Transform Infrared Spectroscopy (FTIR). Surface chemistry of the synthesized AC samples in this study was investigated using FTIR spectroscopy. FTIR spectra for all samples were recorded using Perkin Elmer Spectrophotometer. All measurements were undertaken in the range from 450 to $4000 \mathrm{~cm}^{-1}$ with a resolution of $1 \mathrm{~cm}^{-1}$ for each scan. To prepare samples for the run, all samples of the AC were grounded with $\mathrm{KBr}$ salt at a ratio roughly 1/50 of all samples. After that, these samples were made as pellets. The results of FTIR for AC1, AC2, and AC3 are shown in Figure 8.

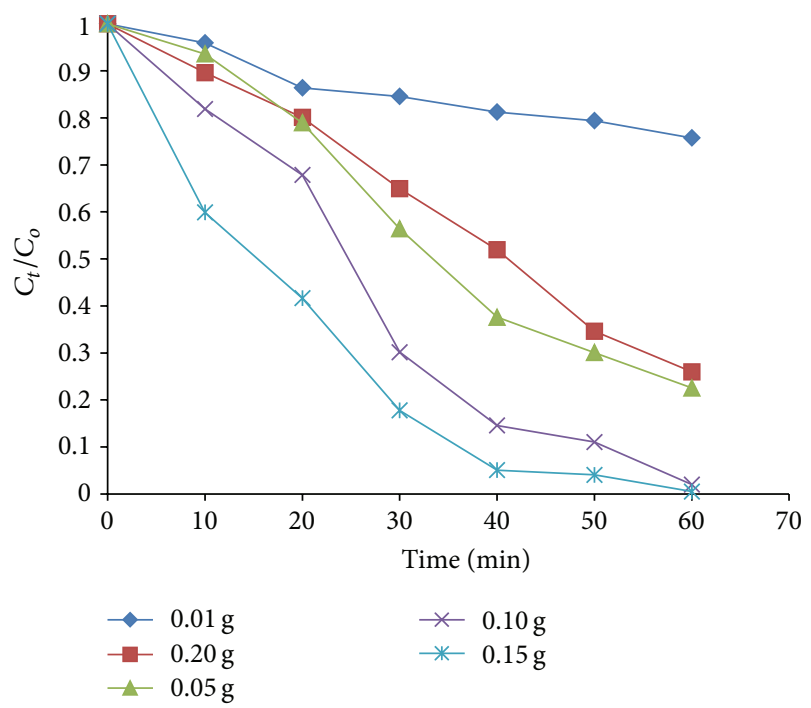

FIgURE 2: The effect of dosage and contact time of $\mathrm{ACl}$ on the removal of BBG dye.

\section{Results and Discussion}

3.1. Effect of Dosage and Contact Time on the Removal of $B B G$. The effects of dosage and contact time for $\mathrm{ACl}$ that was synthesized from palm fronds of IKDP on the removal of BBG from their aqueous solutions are shown in Figure 2. From this figure it can be seen that there was a remarkable increase in the removal of dye with increasing dosage of the used adsorbent (AC1). This probably arises from the increase in the adsorption capacity with increase of the concentration of $\mathrm{ACl}$ in the mixture. The shaking time was one hour at $25^{\circ} \mathrm{C}$ for all experiments that were performed in this work in order to achieve a full equilibration for all doses of the AC types that were synthesized [27]. In terms of the effect of contact time on dye removal also there was a progressive increase in the percentage of dye removal with duration time. This can be attributed to increase uptake capacity of the adsorbent with increase of time and does not reach the maximum adsorption capacity in the range of one hour of adsorption process. These results are shown in Figure 2.

3.2. Study Effect of Type of the AC Samples on Dye Removal. In order to investigate the effect of type of the used AC in the removal of $\mathrm{BBG}$ from the aqueous solutions under the same conditions, a series of experiments were performed using $0.150 \mathrm{~g}$ of each of $\mathrm{ACl}, \mathrm{AC} 2$, and $\mathrm{AC} 3$ at $25^{\circ} \mathrm{C}$ and under shaking for one hour. The obtained results showed that $\mathrm{ACl}$ was more efficient than the other two types of the AC though all of them were synthesized from the same date palm and the same activator was used for all of them. The higher effectiveness of $\mathrm{ACl}$ in relation to the other types probably arises from its relatively higher porosity that is confirmed with relatively higher humidity content for $\mathrm{ACl}$ in comparison with the other two types. It is well known that the activity of catalyst in adsorption is increased with increase of 


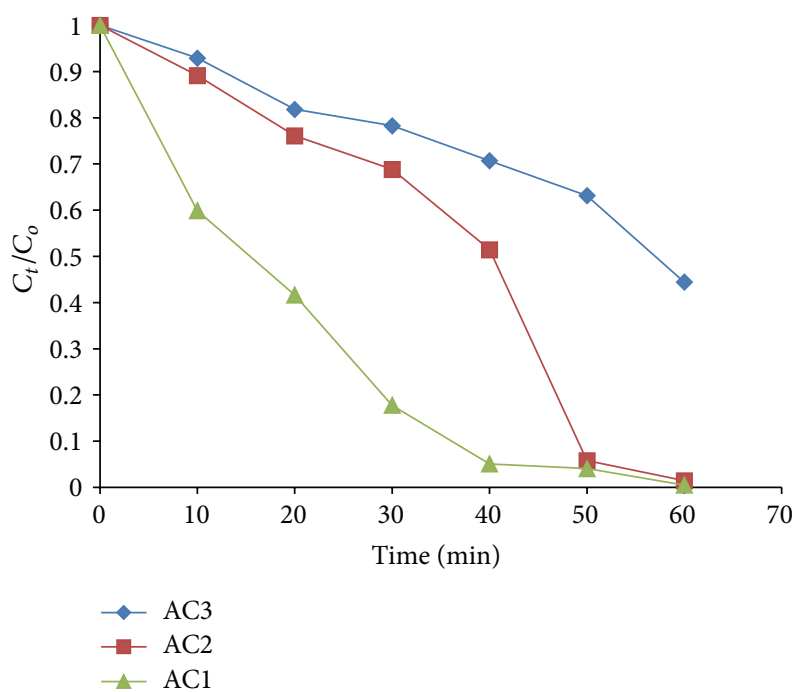

FIGURE 3: Comparison between the efficiency of AC1, AC2, and AC3 on the removal of BBG.

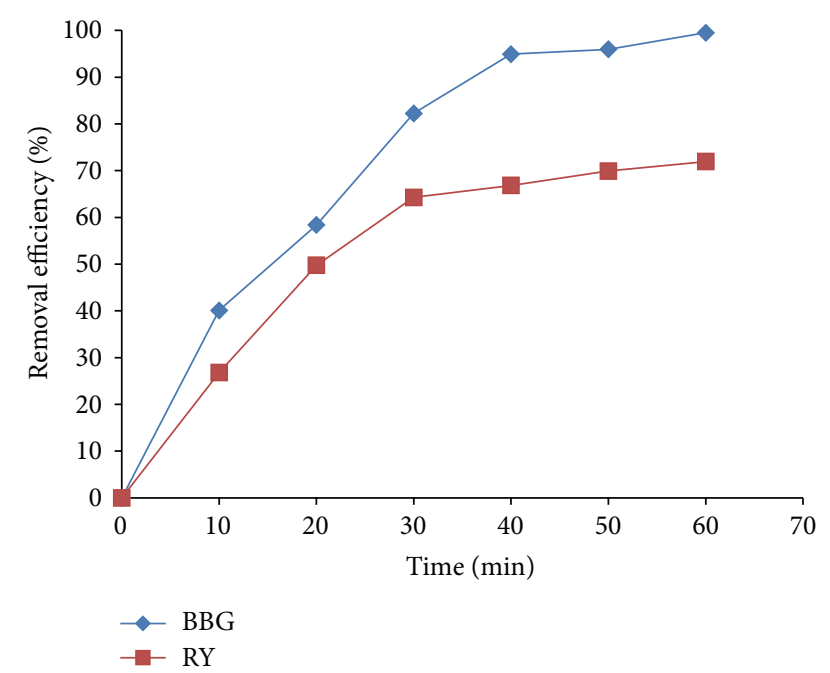

FIGURE 4: Comparison between removal efficiency of BBG and RY145 dyes on AC1.

its porosity. The results of BBG removal on these three types of $\mathrm{AC}$ are shown in Figure 3.

3.3. Effect of Dye Type on the Dye Removal. In order to investigate the effect of the used dye to be adsorbed on $\mathrm{ACl}$, a series of experiments were performed using $40 \mathrm{ppm}$ of each of BBG and RY145 under the same conditions, $40 \mathrm{ppm}$ of each dye in $100 \mathrm{~mL}$ solution, and 0.15 grams of $\mathrm{AC} 1$ at 25 degrees. The results of these dyes removal over $\mathrm{AC1}$ are shown in Figure 4. From these results it is clear that the removal of BBG was more efficient than that for RY145 applying the same adsorption conditions. Removal percentage of BBG approaches hundred percent after only one hour of adsorption duration which is much higher than that for RY145 (around 65\%). This result can be attributed to the effect of diffusion limitation; this factor can have an effect on the adsorption/desorption processes on the surface which normally occur in liquid phase reactions. Reactive yellow dye 145 has bulky structure in comparison with BBG that has a small structure. For this reason BBG is not affected significantly by diffusion limitation as in RY145. However, diffusion limitation factor can have an effect on the rate of the processes that occur in heterogeneous processes in liquid phase and does not significantly affect gas phase processes.

3.4. Adsorption Isotherms. Study of adsorption isotherms was investigated using both Langmuir and Freundlich isotherms for adsorption of BBG dye on the AC1 that was synthesized from IKDP. Langmuir adsorption isotherm is based on the formation of homogeneous monolayer on surface of the adsorbent [28]. For this type of homogeneous adsorption, all adsorption sites are considered to be energetically equivalent. For the physical adsorption, Freundlich equation is applied to follow adsorption isotherm. Both Langmuir and Freundlich isotherms can be explained mathematically as summarized in the following relations $[29,30]$ :

$$
\begin{aligned}
\frac{1}{q_{e}} & =\frac{1}{q_{m}}+\frac{1}{K_{L} q_{m} C_{e}} \quad(\text { Langmuir }) \\
\log q_{e} & =\log K_{F}+\frac{1}{n \log C_{e}} \quad \text { (Freudlich). }
\end{aligned}
$$

The term $q_{e}$ refers to the amount of adsorbate on the adsorbent in $\mathrm{mg} / \mathrm{g}$, or it represents concentration of the $\mathrm{BBG}$ on the $\mathrm{ACl}$, and $q_{m}$ refers to concentration of the $\mathrm{BBG}$ in the solution in $\mathrm{mg} / \mathrm{g}$; it represents capacity of the monolayer adsorption of the adsorbed dye. The term $K_{L}$ refers to Langmuir adsorption constant in $\mathrm{L} / \mathrm{mg}$. The term $C_{e}$ refers to concentration of dye in the equilibrium in $\mathrm{mg} / \mathrm{L}$ and both $K_{f}$ and $1 / n$ are the constants of Freundlich adsorption isotherm.

As mentioned above, maximum adsorption capacity for the $\mathrm{ACl}$ can be obtained using Langmuir equation. In this context, reaction conditions that were applied in this part were as follows: temperature was $25^{\circ} \mathrm{C}, \mathrm{pH} 5.5$, and the initial concentration of $\mathrm{BBG}$ was $40 \mathrm{ppm}$. The amount of the used $\mathrm{ACl}$ ranged from 0.05 to $0.20 \mathrm{~g}$ with increasing rate of $0.05 \mathrm{~g}$ for each dose. The obtained results for the isotherms constants and for the $R^{2}$ are summarized in Table 1 . These results are represented graphically in Figures 5 and 6 as $1 / q_{e}$ against $1 / C_{e}$. These results were more fitted with Freundlich isotherm. This arises from a high value of correlation coefficient for these results.

3.5. Uptake Capacity of the Synthesized Activated Carbon. The uptake adsorption capacity of AC1, AC2, and AC3 was investigated by following the adsorption of $\mathrm{MB}$ from the aqueous solution. The results of uptake $\mathrm{MB}$ by $\mathrm{AC}$ samples are presented in Table 2 as $\mathrm{mg} / \mathrm{g}$. From the obtained results it is clear that these types of AC showed high adsorption capacity and this indicated that these materials have a high porosity in their structures [31]. High adsorption capacity of these types of AC enables them to adsorb materials with high efficiency. The ability of adsorption is mainly dependent on the pores structure and the pores volume. 
TABLE 1: Langmuir and Freundlich isotherm constants.

\begin{tabular}{lcc}
\hline Isotherms & Constants/correlation coefficients & Values \\
\hline \multirow{3}{*}{ Langmuir } & $R^{2}$ & 0.9508 \\
& $q_{m}$ & 65.7894 \\
& $K_{L}$ & 0.49673 \\
\hline \multirow{3}{*}{ Freundlich } & $R^{2}$ & 0.6407 \\
& $K_{F}$ & 21.9280 \\
& $N$ & 2.3798 \\
\hline
\end{tabular}

TABLE 2: Adsorption capacity for the synthesized AC by MB adsorption.

\begin{tabular}{lc}
\hline Type of AC & Uptake capacity of AC $(\mathrm{mg} / \mathrm{g})$ \\
\hline AC1 & 199.8 \\
AC2 & 199.4 \\
AC3 & 198.8 \\
\hline
\end{tabular}

TABLE 3: The percentage of moisture content for AC samples.

\begin{tabular}{lc}
\hline Type of AC & Humidity\% \\
\hline AC1 & 48 \\
AC2 & 46 \\
AC3 & 45 \\
\hline
\end{tabular}

TABLE 4: PZC for AC1, AC2, and AC3 samples synthesized from IKDP.

\begin{tabular}{lc}
\hline Type of AC & pH of AC \\
\hline AC1 & $8.25 \pm 0.10$ \\
AC2 & $8.62 \pm 0.12$ \\
AC3 & $8.45 \pm 0.15$ \\
\hline
\end{tabular}

3.6. Humidity of the Synthesized Activated Carbon. The humidity content of the synthesized AC arises from the ability of $\mathrm{AC}$ to absorb moister into the prose structure when it is subjected to humid ambient conditions. However, from the obtained results in this study it was found that there is a relatively high content of humidity for all $\mathrm{AC}$ types in this work. So these materials can be considered as good adsorbents for many types of adsorbate and can be used in different applications as in analytical and chromatographic methods and industrial and environmental applications [32, 33]. The percentages of humidity content for $\mathrm{AC} 1, \mathrm{AC} 2$, and AC3 samples are presented in Table 3.

3.7. The Point Zero Charges of the Activated Carbon (PZC). The PZC of the AC samples synthesized from three different positions of IKDP was estimated according to potentiometric method [26]. The results of the PZCs for these materials are presented in Table 4. From these results it is clear that all the samples showed weak alkaline $\mathrm{pH}$ values ranging from 8.25 to 8.62 . However, the lowest $\mathrm{pH}$ value was assigned to the $\mathrm{ACl}$ and the highest value was assigned to the $\mathrm{AC} 2$ sample. Generally, these values of PZCs are dependent on the presence of proton and hydroxyl groups on the surface of AC samples. Thus, the presence of acidic and/or basic impurities

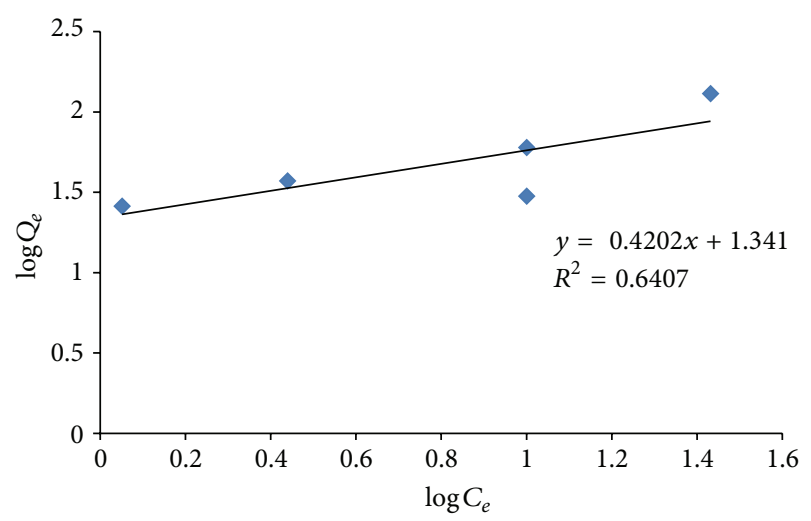

FIGURE 5: The linear Freundlich adsorption isotherms for BBG dye adsorption by the $\mathrm{ACl}$.

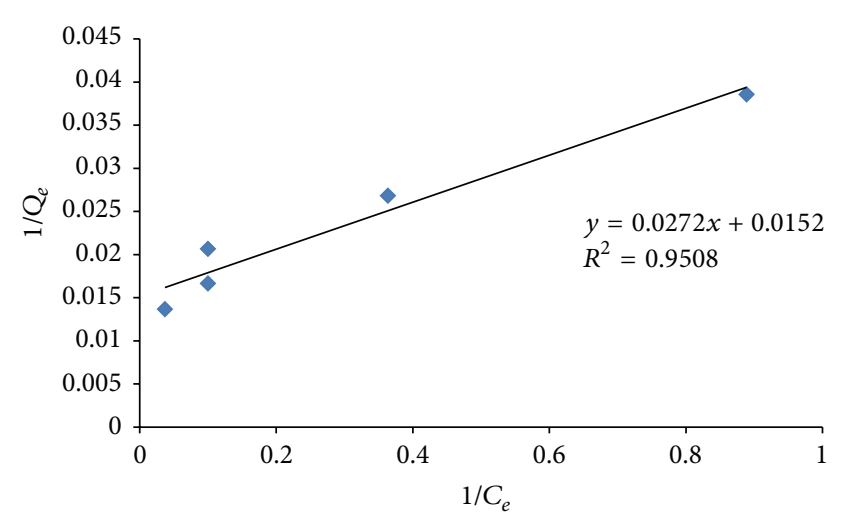

FIGURE 6: The linear Langmuir adsorption isotherms for BBG dye adsorption by the ACl.

on the surface of AC samples can have an effect on the value of the PZCs of these materials.

3.8. Scanning Electron Microscopy (SEM). Morphology of the synthesized AC was studied using SEM technique. SEM images of these materials showed irregular distribution with heterogeneous morphology of the surface. These images showed the presence of pores and cavities for all activated carbon samples. High porosity and irregularity can be seen with samples of $\mathrm{ACl}$ and $\mathrm{AC} 2$ more than $\mathrm{AC} 3$ samples. The increase in porosity and cavities for these materials results in the enhancement of adsorption capacity that enables these materials to adsorb high concentrations of the adsorbates and accordingly they can have high efficiency as adsorbent materials and they can be applied in many of the environmental and industrial applications. Morphological images of these types of AC samples are shown in Figure 7.

3.9. Fourier Transform Infrared Spectroscopies of AC Samples (FTIR). In general the FTIR spectra for all the samples of AC that we synthesized from IKDP were almost the same. FTIR spectra of the AC showed three main absorption bands in the region from 1400 to $1700 \mathrm{~cm}^{-1}$. The band that appears around $1700 \mathrm{~cm}^{-1}$ is related to the stretching modes of $\mathrm{C}=\mathrm{O}$ bonds. 


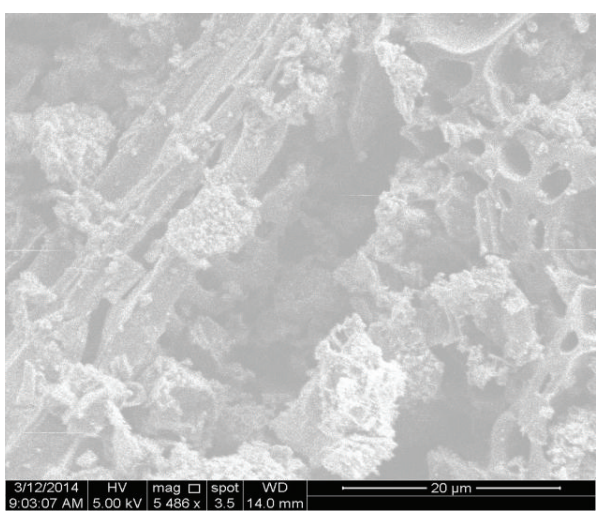

$\mathrm{AC} 1$

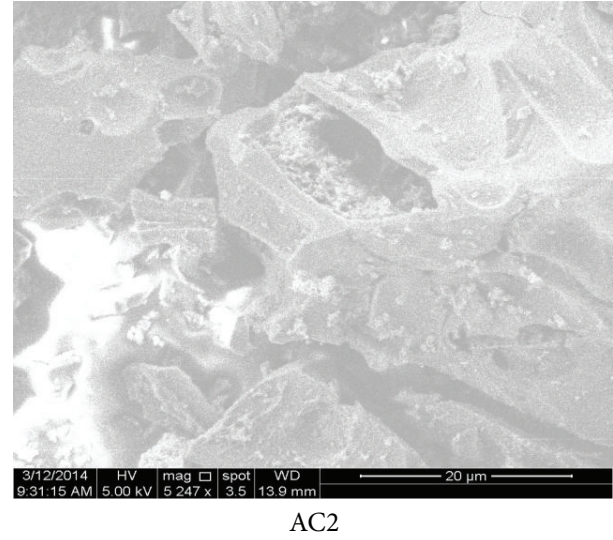

$\mathrm{AC} 2$

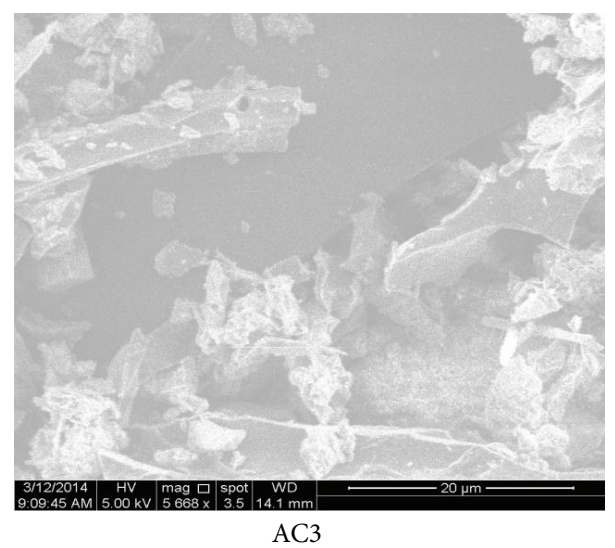

FIGURE 7: SEM images for the AC1, AC2, and AC3 samples synthesized from IKDP.

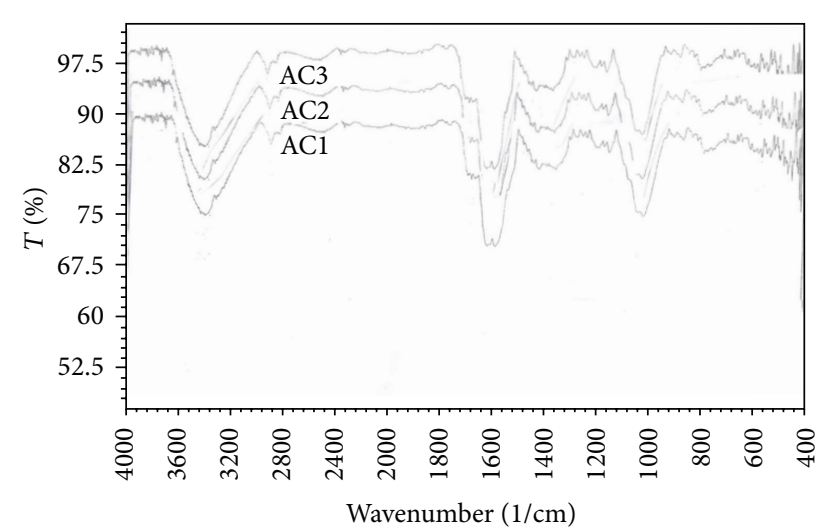

FIGURE 8: FTIR spectra for AC1, AC2, and AC3 samples synthesized from IKDP.

The band that appears around $1425 \mathrm{~cm}^{-1}$ can be assigned to the stretching vibrations of C-C bonds [34]. Strong band around $1600 \mathrm{~cm}^{-1}$ is related to the stretching vibrations of bonds of aromatic rings, those coupled with conjugated carbonyl groups on the surface [35]. The stretching modes of $\mathrm{C}=\mathrm{O}$ bonds can be seen around $1100-1200 \mathrm{~cm}^{-1}$. In all samples of $\mathrm{AC}$, there were weak peaks around $3000 \mathrm{~cm}^{-1}$ indicating the presence of the unsaturated alkynes $\mathrm{C}=\mathrm{C}$ stretching modes; the peaks around 600 to $850 \mathrm{~cm}^{-1}$ confirmed vibration of $\mathrm{C}-\mathrm{H}$ bending mode [36]. Bands around
$3500-3600 \mathrm{~cm}^{-1}$ are assigned to the stretching modes which are related to $\mathrm{OH}$ groups. From these peaks, it can be seen that all these three samples of AC have almost the same oxygenated surface functional groups that are present on the surface of the synthesized AC. FTIR spectra for AC1, AC2, and AC3 are shown in Figure 8.

\section{Conclusions}

This study showed that an activated carbon can be prepared from raw widely available agricultural materials in Iraq such as date palms. This prepared AC can be used as an efficient adsorbent for wide range of materials. Also this study proved that $\mathrm{ACl}$ that was derived from palm fronds of IKDP showed higher efficiency for removal of the BBG in comparison with $A C 2$ and AC3. The synthesized AC samples showed high adsorption capacities, so that these AC samples can be used as good adsorbent materials. Also the synthesized materials showed relatively high humidity content which means that these materials have high porosity structure. These properties are considered as encouraging physical properties for these materials to be used as adsorbent material.

\section{Conflict of Interests}

The authors declare that there is no conflict of interests regarding the publication of this paper. 


\section{References}

[1] R. H. Hesas, A. Arami-Niya, W. M. A. Wan Daud, and J. N. Sahu, "Preparation and characterization of activated carbon from apple waste by microwave-assisted phosphoric acid activation: application in methylene blue adsorption," BioResources, vol. 8, no. 2, pp. 2950-2966, 2013.

[2] Z. Al-Qodah and R. Shawabkah, "Production and characterization of granular activated carbon from activated sludge," Brazilian Journal of Chemical Engineering, vol. 26, no. 1, pp. 127136, 2009.

[3] Z. Jiang, Y. Liu, X. Sun et al., "Activated carbons chemically modified by concentrated $\mathrm{H}_{2} \mathrm{SO}_{4}$ for the adsorption of the pollutants from wastewater and the dibenzothiophene from fuel oils," Langmuir, vol. 19, no. 3, pp. 731-736, 2003.

[4] T. Vidhyadevi, A. Murugesan, S. S. Kalaivani et al., "Optimization of the process parameters for the removal of reactive yellow dye by the low cost Setaria verticillata carbon using response surface methodology: thermodynamic, kinetic, and equilibrium studies," Environmental Progress and Sustainable Energy, vol. 33, no. 3, pp. 855-865, 2014.

[5] A. A. Athab, A. J. Lafta, and F. H. Hussein, "Modification of carbon nanotubes surface using different oxidizing agents," Environmental Analytical Chemistry, vol. 2, no. 3, pp. 1-2, 2015.

[6] G. J. Muhammed, F. H. Abdulrazzak, and F. H. Hussein, "Synthesis of multi-walled carbon nanotube by using ethanol as a carbon source," Chemical Sciences Journal, vol. 6, pp. 1-2, 2015.

[7] F. H. Abdulrazzak and F. H. Hussein, "Effects of nanoparticle size on catalytic and photocatalytic activity of carbon nanotubes-titanium dioxide composites," Environmental Analytical Chemistry, vol. 2, pp. 1-2, 2014.

[8] M. A. Shaheed and F. H. Hussein, "Preparation and applications of titanium dioxide and zinc oxide nanoparticles," Environmental Analytical Chemistry, vol. 2, pp. 1-3, 2015.

[9] A.-N. A. El-Hendawy, "Influence of $\mathrm{HNO}_{3}$ oxidation on the structure and adsorptive properties of corncob-based activated carbon," Carbon, vol. 41, no. 4, pp. 713-722, 2003.

[10] S. Rengaraj, S.-H. Moon, R. Sivabalan, B. Arabindoo, and V. Murugesan, "Agricultural solid waste for the removal of organics: adsorption of phenol from water and wastewater by palm seed coat activated carbon," Waste Management, vol. 22, no. 5, pp. 543-548, 2002.

[11] F. Rozada, M. Otero, A. Morán, and A. I. García, "Activated carbons from sewage sludge and discarded tyres: production and optimization," Journal of Hazardous Materials, vol. 124, no. 1-3, pp. 181-191, 2005.

[12] K. Imamura, E. Ikeda, T. Nagayasu, T. Sakiyama, and K. Nakanishi, "Adsorption behavior of methylene blue and its congeners on a stainless steel surface," Journal of Colloid and Interface Science, vol. 245, no. 1, pp. 50-57, 2002.

[13] J. H. Ko, K. S. Choi, H. J. Woo, H. I. Lee, and C. W. Kim, "Evaluation of $\mathrm{pH}$ inhibition effect on activated sludge by the pseudo toxic concentration (CPT) concept model," Water Science and Technology, vol. 43, no. 7, pp. 65-72, 2001.

[14] T. Budinova, E. Ekinci, F. Yardim et al., "Characterization and application of activated carbon produced by $\mathrm{H}_{3} \mathrm{PO}_{4}$ and water vapor activation," Fuel Processing Technology, vol. 87, no. 10, pp. 899-905, 2006.

[15] A. Niya, W. Daud, F. Mjalli, F. Abnisa, and S. Shafeeyan, "Production of microporous palm shell based activated carbon for methane adsorption: modeling and optimization using response surface methodology," Chemical Engineering Research and Design, vol. 90, no. 6, pp. 776-784, 2012.

[16] A. Niya, F. Abnisa, M. Shafeeyan, W. Daud, and N. Sahu, "Optimization and characterization of palm shell-based biochar as a by-product of bio-oil production process," Biological Resources, vol. 7, no. 1, pp. 246-264, 2012.

[17] F. Suárez-García, A. Martínez-Alonso, and J. M. D. Tascón, "Pyrolysis of apple pulp: effect of operation conditions and chemical additives," Journal of Analytical and Applied Pyrolysis, vol. 62, no. 1, pp. 93-109, 2002.

[18] E. Yagmur, M. Ozmak, and Z. Aktas, "A novel method for production of activated carbon from waste tea by chemical activation with microwave energy," Fuel, vol. 87, no. 15-16, pp. 3278-3285, 2008.

[19] P. Nigam, G. Armour, I. M. Banat, D. Singh, and R. Marchant, "Physical removal of textile dyes from effluents and solidstate fermentation of dye-adsorbed agricultural residues," Bioresource Technology, vol. 72, no. 3, pp. 219-226, 2000.

[20] S. J. Allen, G. McKay, and K. Y. H. Khader, "Equilibrium adsorption isotherms for basic dyes onto lignite," Journal of Chemical Technology and Biotechnology, vol. 45, no. 4, pp. 291302, 1989.

[21] F. Hussein, A. Halbus, F. Abdalrazak, and Z. Athab, "Adsorptionof cobalamin onto synthesized carbon nanotubes (CNT)," Journal of Applicable Chemistry, vol. 2, pp. 589-604, 2013.

[22] A. F. Halbus, Z. H. Athab, and F. H. Hussein, "Adsorption of disperse blue dye on Iraqi date palm seeds activated carbon," International Journal of Chemical Sciences, vol. 11, no. 3, pp. 1219-1233, 2013.

[23] A. Kamil, F. Abdalrazak, A. Halbus, and F. Hussein, "Adsorption of bismarck brown R dye onto multiwall carbon nanotubes," Journal of Environmental Analytical Chemistry, vol. 1, pp. 1-6, 2014.

[24] O. Vohler, E. Vonsturn, H. Vonkienel, and P. Chmit, Ullmann's Encyclopedia of Industrial Chemistry, John Wiley \& Sons, Berlin, Germany, 5th edition, 1986.

[25] J. Guo and A. C. Lua, "Textural and chemical properties of adsorbent prepared from palm shell by phosphoric acid activation," Materials Chemistry and Physics, vol. 80, no. 1, pp. 114-119, 2003.

[26] J. Vakros, C. Kordulis, and A. Lycourghiotis, "Potentiometric mass titrations: a quick scan for determining the point of zero charge," Chemical Communications, vol. 8, no. 17, pp. 1980-1981, 2002.

[27] R. Katal, M. S. Baei, H. T. Rahmati, and H. Esfandian, "Kinetic, isotherm and thermodynamic study of nitrate adsorption from aqueous solution using modified rice husk," Journal of Industrial and Engineering Chemistry, vol. 18, no. 1, pp. 295-302, 2012.

[28] R. Sivaraj, R. Venckatesh, G. Gowri, and G. Sangeetha, "Activated carbon from eichornia crassipes as an adsorbent for the removal of dyes from aqueous solution," International Journal of Engineering Science and Innovative Technology, vol. 2, no. 6, pp. 2418-2427, 2010.

[29] C. K. Ahn, D. Park, S. H. Woo, and J. M. Park, "Removal of cationic heavy metal from aqueous solution by activated carbon impregnated with anionic surfactants," Journal of Hazardous Materials, vol. 164, no. 2-3, pp. 1130-1136, 2009.

[30] C. S. Sundaram, N. Viswanathan, and S. Meenakshi, "Defluoridation chemistry of synthetic hydroxyapatite at nano scale: equilibrium and kinetic studies," Journal of Hazardous Materials, vol. 155, no. 1-2, pp. 206-215, 2008. 
[31] D. Özer, G. Dursun, and A. Özer, "Methylene blue adsorption from aqueous solution by dehydrated peanut hull," Journal of Hazardous Materials, vol. 144, no. 1-2, pp. 171-179, 2007.

[32] J. Li, Z. Li, B. Liu, Q. Xia, and H. Xi, "Effect of relative humidity on adsorption of formaldehyde on modified activated carbons," Chinese Journal of Chemical Engineering, vol. 16, no. 6, pp. 871875, 2008.

[33] A. Lafta, A. Halbus, F. Daabool, Z. Burhan, H. Fenoon, and F. Hussein, "Adsorption of reactive yellow-145 dye on activated carbon," International Journal of Chemistry, vol. 3, no. 2, pp. 179$183,2014$.

[34] J. Sahira, A. Mandira, P. Prasad, and P. Ram, "Effects of activating agents on the activated carbons prepared from lapsi seed stone," Research Journal of Chemical Sciences, vol. 3, no. 5, pp. 19-24, 2013.

[35] E. Ekinci, T. Budinova, F. Yardim, N. Petrov, M. Razvigorova, and V. Minkova, "Removal of mercury ion from aqueous solution by activated carbons obtained from biomass and coals," Fuel Processing Technology, vol. 77-78, pp. 437-443, 2002.

[36] K. Venkatachalam, P. Visuvamithiran, B. Sundaravel, M. Palanichamy, and V. Murugesan, "Catalytic performance of AlMCM-48 molecular sieves for isopropylation of phenol with isopropyl acetate," Chinese Journal of Catalysis, vol. 33, no. 2-3, pp. 478-486, 2012. 

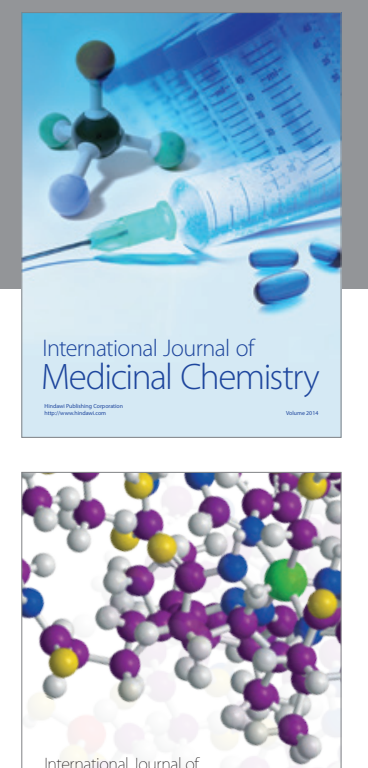

\section{Carbohydrate} Chemistry

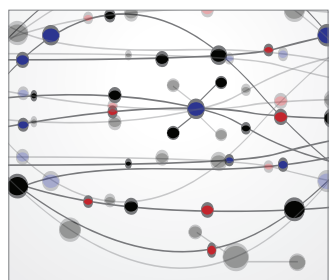

The Scientific World Journal
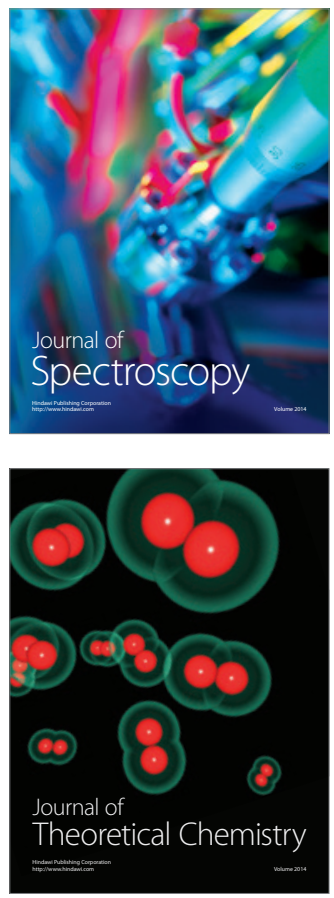
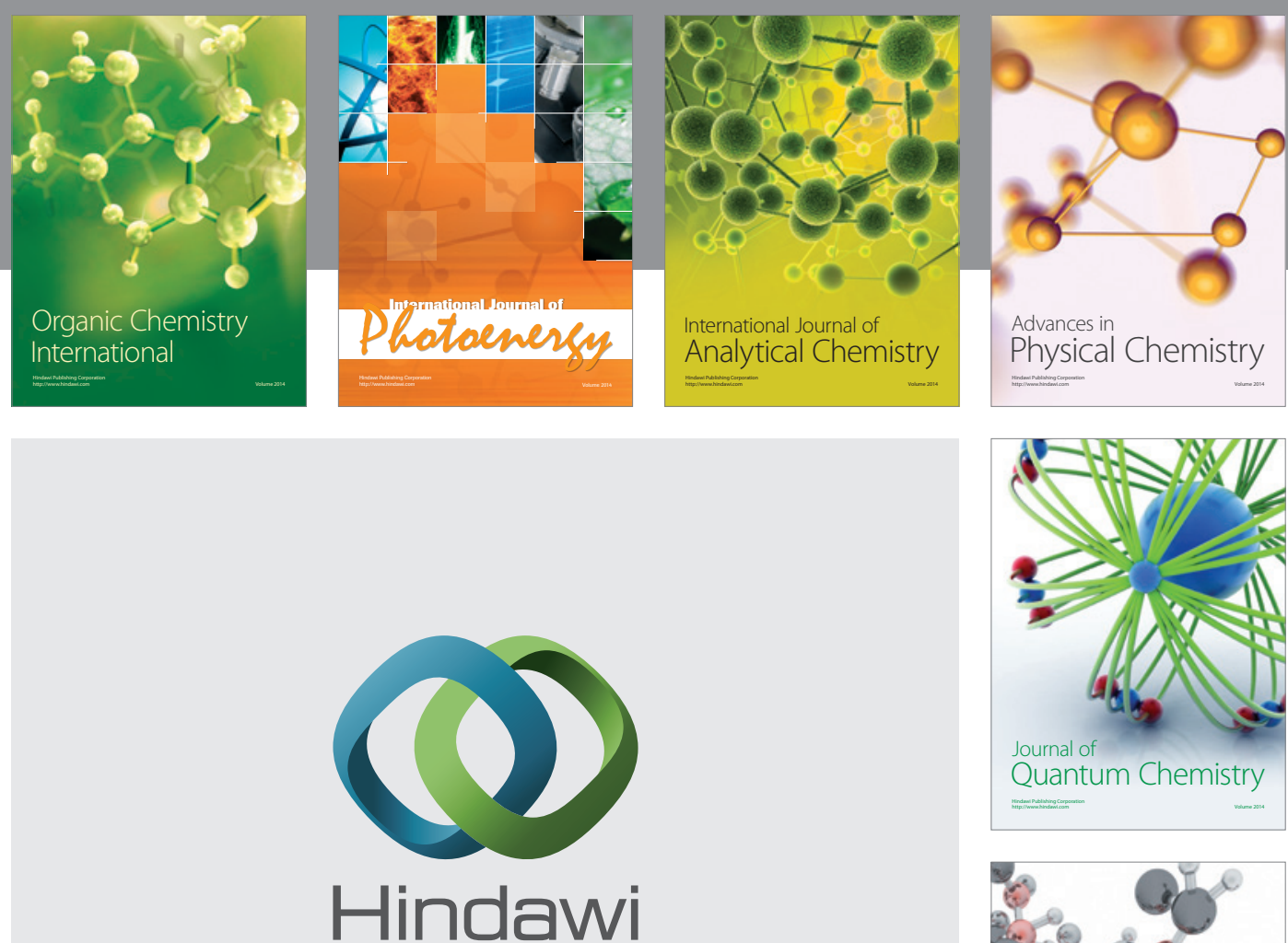

Submit your manuscripts at

http://www.hindawi.com

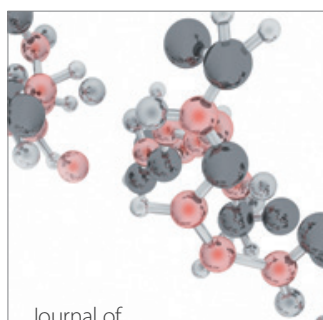

Analytical Methods

in Chemistry

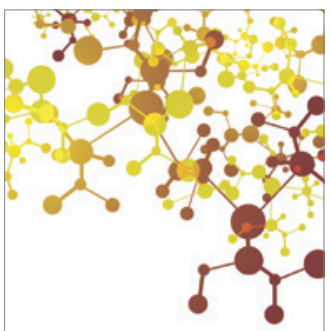

Journal of

Applied Chemistry

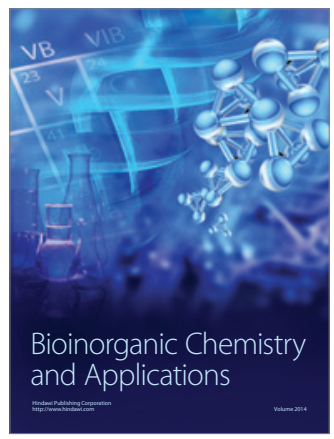

Inorganic Chemistry
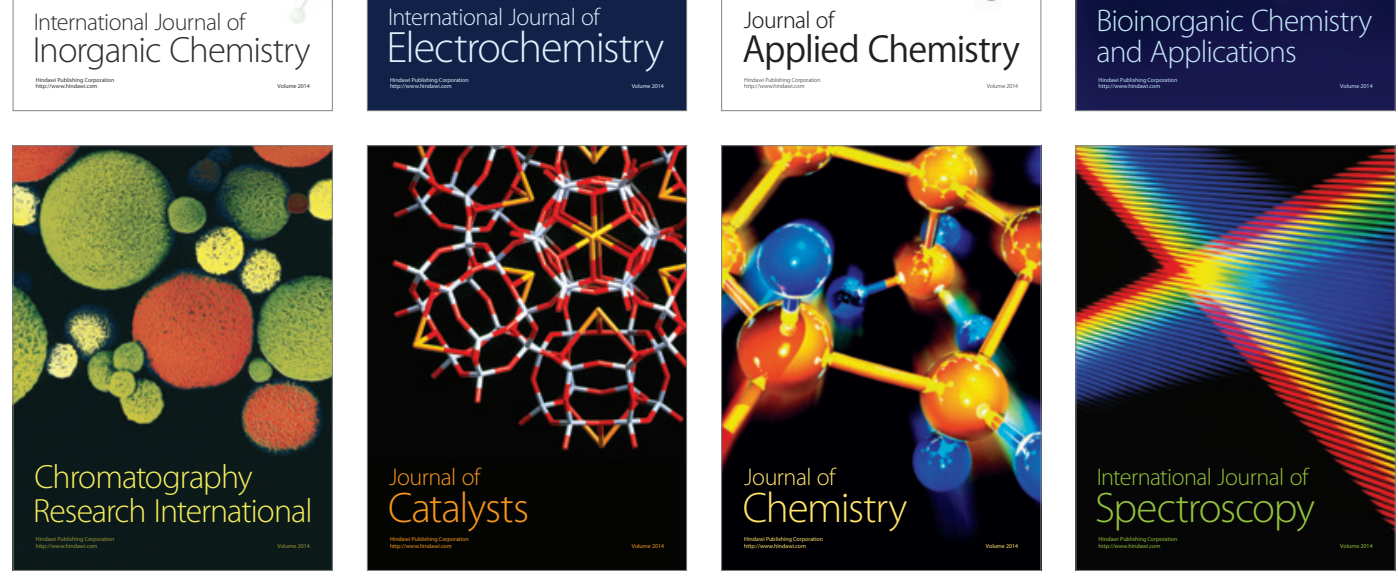